\title{
Het geheim van de ontaarde crypt
}

Citation for published version (APA):

Blijham, G. H. (1990). Het geheim van de ontaarde crypt. Rijksuniversiteit Limburg. https://doi.org/10.26481/spe.19900629gb

Document status and date:

Published: 29/06/1990

DOI:

10.26481/spe.19900629gb

Document Version:

Publisher's PDF, also known as Version of record

\section{Please check the document version of this publication:}

- A submitted manuscript is the version of the article upon submission and before peer-review. There can be important differences between the submitted version and the official published version of record.

People interested in the research are advised to contact the author for the final version of the publication, or visit the DOI to the publisher's website.

- The final author version and the galley proof are versions of the publication after peer review.

- The final published version features the final layout of the paper including the volume, issue and page numbers.

Link to publication

\footnotetext{
General rights rights.

- You may freely distribute the URL identifying the publication in the public portal. please follow below link for the End User Agreement:

www.umlib.nl/taverne-license

Take down policy

If you believe that this document breaches copyright please contact us at:

repository@maastrichtuniversity.nl

providing details and we will investigate your claim.
}

Copyright and moral rights for the publications made accessible in the public portal are retained by the authors and/or other copyright owners and it is a condition of accessing publications that users recognise and abide by the legal requirements associated with these

- Users may download and print one copy of any publication from the public portal for the purpose of private study or research.

- You may not further distribute the material or use it for any profit-making activity or commercial gain

If the publication is distributed under the terms of Article $25 \mathrm{fa}$ of the Dutch Copyright Act, indicated by the "Taverne" license above, 
Het Gehelw van de ontaarde Crypt

Rede, ultgesproken bij de tanvaarding wan thet thbt van Hoogleraar in de Invendige Geneeskunde, in het bizonder de Medische oncologle, an de Rijksuniversiteit Limburg te Mastricht op vrifdag 29 junl 1990

door

Dr. G. Blijhan 


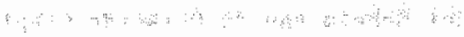

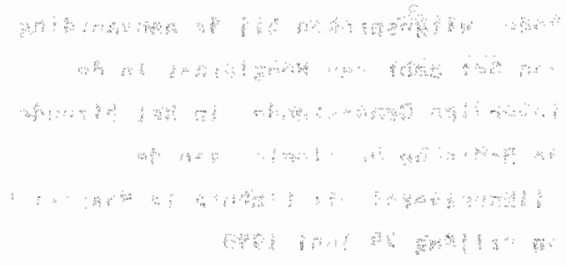

What and a 


\section{Yoorwoord}

We een Intreerede voorbereldt, raakt spoed in het ongerede. Te talnjh an

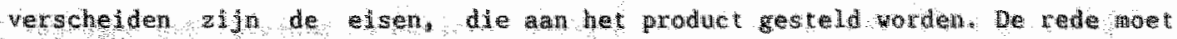
getugen yan de geleerdneld van de niewwakken hooglerar, een hindrugeven van

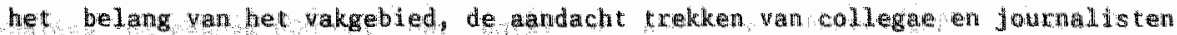

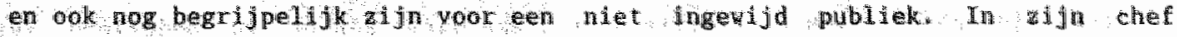

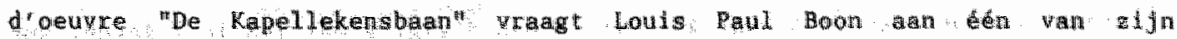
personages, de kantleke schoolaees ter, een ootded aver ziljn romsu. De hant leke schoolmeester antwoordt Boon: wat er in Uh boek ontbrekt, is wat ex teveel In

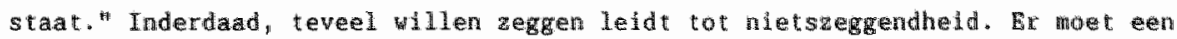
keuze worden gemakt en daarvan 1 deze Inlelding een korte verantwoonding zijn. Ik heb ervoor gekozen met deze rede cen globale indruk te geven wan het soort problemen, dat een internis met ancologische specialisatie in 1990 bezighoudt. Voor de illustrates, die nodig zijn on deze probilemen thanden en

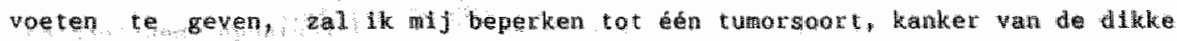
dart. Bly het zoeken mar een geschikte worm an deze problemen te ordenen viel mij de analogie tussen oncologie cn crinaliteit op. Tunoren worden vaak als moprdenars van binmer uit gevoeld, genezen patienten ondervinden probletwen die aok van slachtoffers van misdaden bekend ailn en acadentache internistoncologen paren, net als goede speurders, compassie an nieurgterigheid. pit alles heeft geleid tot het misdaadverhaal waruit ik $U$, wanuldag ga vorlezen

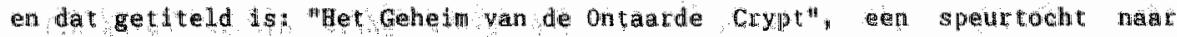
vóckomen on ts taan eq behandelling ran kanker van de dikke darm.

Hoofdstuk I, De Hisdaad.

In Nederland stlerven in 19874297 mensen an karker van de dikke darn. Daraton hadden 1046 patienten een recturcarcinoon, diat wil zeggen een tumor van de laatste 10 ch van de dike darm en 3251 een carcinoon wan het vel langere. hoger gelegen gedelte van de dikke darn, bet colon. Deze sterte betekent $3,5 \%$

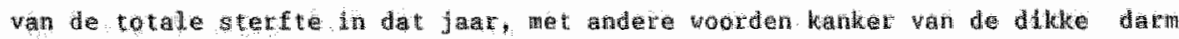

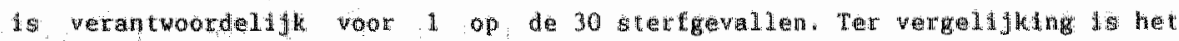
interessant te weten, dat in 1907136 personen dowt moord, 1616 pertsonen door

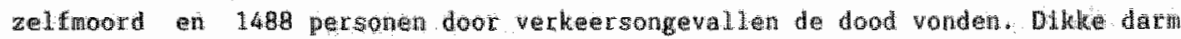
kanker dragt dus meer an de jaarlijkse sterte blj dan cuthinalitelt eth verkeer geztinenlijk. Van alle tumoren is het colorectale carcinoon de twede in sterte en voorkomen na longkanker. War de hileuwe gevallen wan katker bestat 


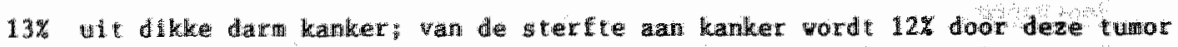

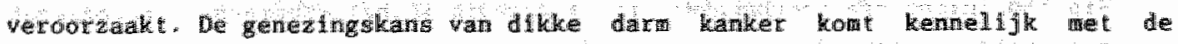

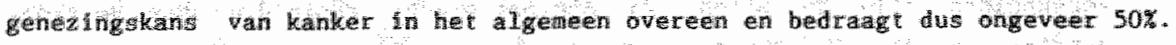

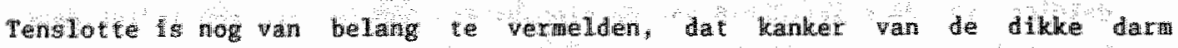
wonewh. Ongarekend nar eem bevolking wan 100.000 mensen wet genddelde

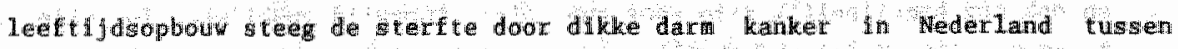

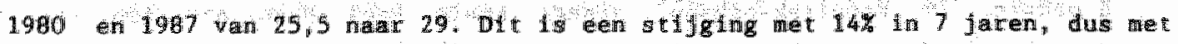

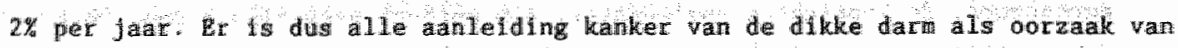

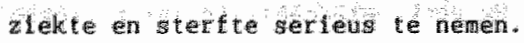

Hordstuh I de Slacheoter

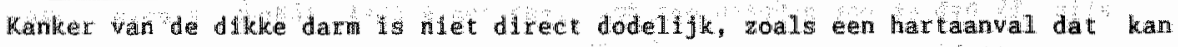

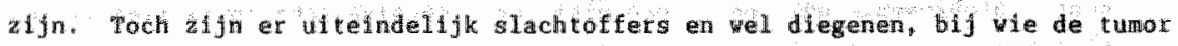

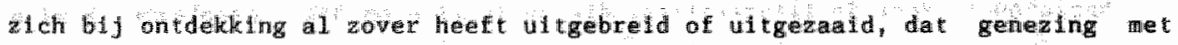

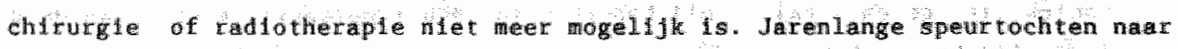

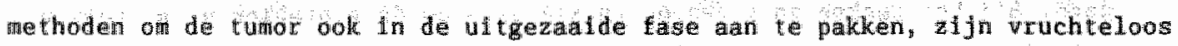
geblekell. Wanker van de dikk darm is bijna net gewoellg voot behandellng net

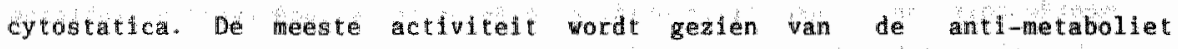

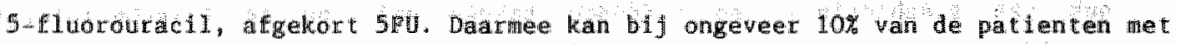
colorectad carcinoon en verkderning van de tunor inet minstent sos worden

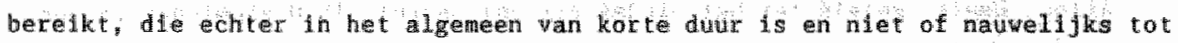

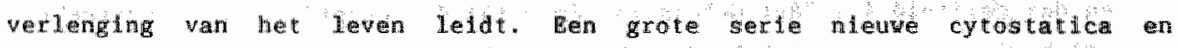
coblnates van cytostalca ls geprobeerd, echter zonder succes. In deze situtie die veel internistoncologen terech pessinistisch heeft gestemd over

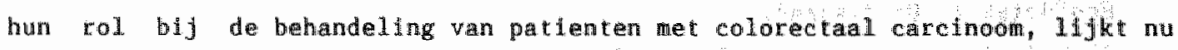
verander ing te konen.

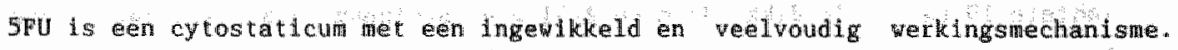
Dat biedt anknoping purten on te trachen de efectivitelt te wersterken door

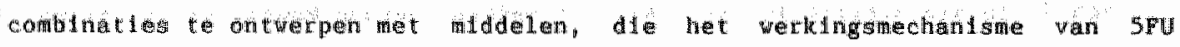

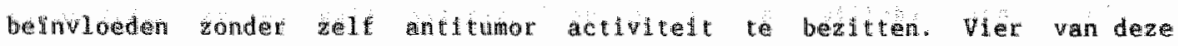

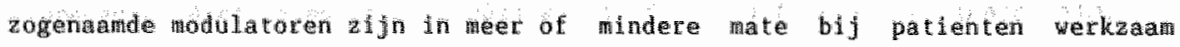
geblekent Leucovorin, methotramat, PALA en dinter feron. 
Kanker wan de Dikke Darm : Chenotheraphe aet Huorouracll en Hodulatoren

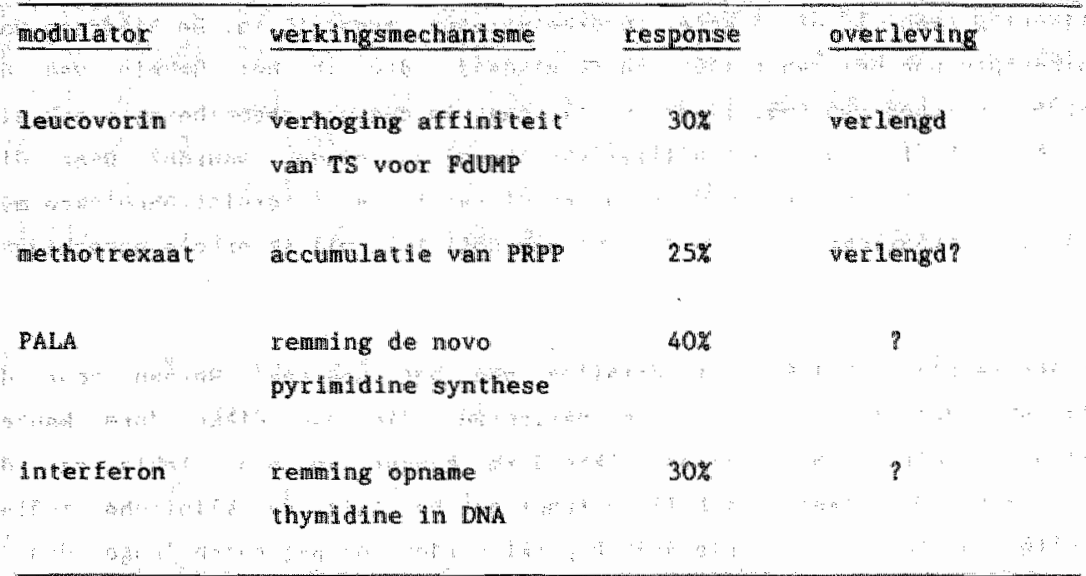

bronnen: Einhorn, JCO 1989; Blijham, Stratsburg 1989, ASCO 1990;

Ernstof, JCO 1989 .

Wellicht de bekendste combinatie is die van 3 FU met het gereduceerde folat leucavorin. Met deze combinatle wordt bij 1 op 3 a 4 in plats van 1 op 10 patienten een positief effect gezlen en dit effect leldt tot een verlenglng van de gemiddelde levensverwachting met enkele manden. In én van de studies is ook een verbetering van de kwaltelt van leven vastgesteld. Methotrexeat

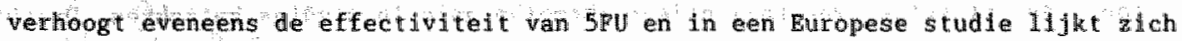
tevens een verleming van de overleving af te tekenen. Van combinatles met PaLA en interferon zijn nog geen vergelijkende $s$ tudies met $5 F U$ alleen bekend. In niet-vergel jkend onderzoek is van de PALA-5FU combinatie en activiteft van ongeveer $40 \%$ vastgesteld. In Europees verband bestaan woornemens met deze

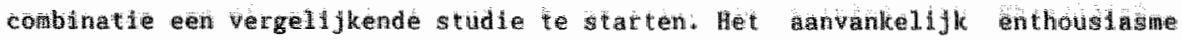

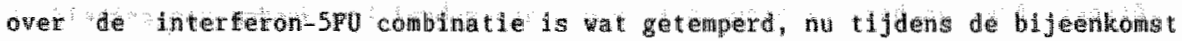
van de American Soclety fox Clintcal oncology in mel 1990 i studles $21 \mathrm{fn}$ gerapporteerd, warin bij ongeveer $30 \%$ in plats wan de cerst gemelde box wan de patienten duldelijke afname van de tumor kon wotden vastgesteld. 
Mei deze regultaten, hoe belanguekterd ook, is het probleen dilke darn kanker

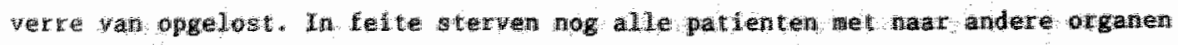

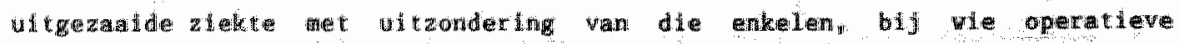

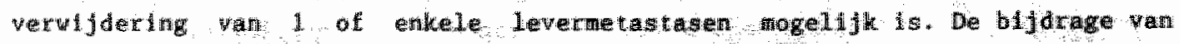

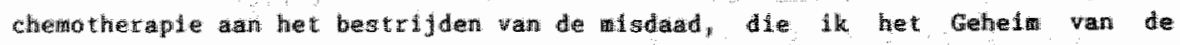
ontarde crypt heb genoend, Is dus $n$ hil , max 15 datare chemotheraple ook als vorf van slachtoterbilp, als pallatieve herapie, zonder waarde? over dit punt, ew valk terugkerend onderwerp van discussie van intemist-oncologen met

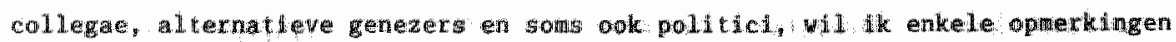
iniakren.

In de eerste plate blifkt ult getallen wan het central Bureau voor de statistlek, dat twederde van de patiaten, die aan dikke dara kanker overlifden, ouder 19 dan 70 jaren. Dikke darm kanker, 1 sen tekte wan de oudere mens. Dat staat in schrll contrast met het felt, dat kIinische studies naar effecten wan chemotheraple wak beperk worden tot pattenten jonger dan 70

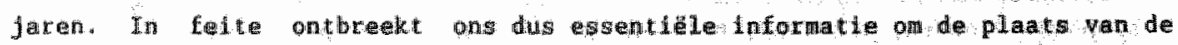
meutre wormen van palliatleve theraple goed te bepalen. Nat mijn oordeel dient kliniset andwzoek van chemotheraple blf oudere patienten te worden gestmuleerd, bifwoorbeeld door de Europese organtsatie op dit terrelninde EORTC, of door de Comissie Klinisch Vergelijkend Onderzoelk, ckva, van de Nederlandse Kankerbestrijding.

In de twede plats 1 s de kwaliteit van leven tot nu to onvoldoende als mat yoor de affecten wan palliatleve chenotheraple in studles betrokiken Dararbij pleft ik nilet wor het afnetiem van lange vragenlijsten over alle denkbare menselijke functies , mar an simpele zell in te vullen enquêtes, warmee een Indruk wordt verkregen over de mate van mobiliteit, zelfredaanheid, sociale activiteit, stemmingsproblemen en piyn. onderzoeksresultaken zoals nu bekend

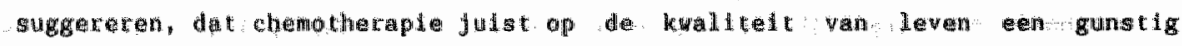
affect kan hebten. Inden dit op grotere schal kan worden vastgesteld; kan weel yooroonder en subjoctivitel uit de genoende discussie over palliatleve chenotheraple worden verwijderd. 
In de derde plaats noet het we van het hat dat als we wee worlge apnerkingen betrekling hebben op tekortkomingen In ons algen speurther de Intemist-oncollogen tegelifkertju moeten worden gecomplinenteer mec de

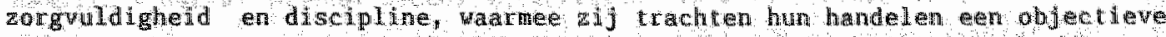
basts te geven. Dit staat in schril contrast met de absoluut ongefunderevde

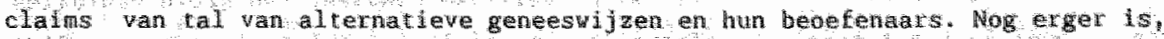
dat de staatssecretaris recent een exkend ben beten ineffectiel genesmidel woor pergoeding heeft gehandhated, ondat zoveel pat tenten eraan roudan hechten. Ik aeht een dergelijk besiult beledigend por alle klinisch onderzowkers, die

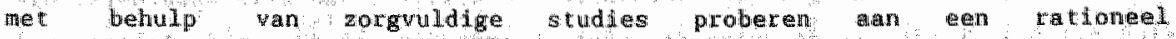
geneesmiddelengebruik bij te dragen.

Met deze 3 opmerkingen kom ik aan de vraag, wat op dit moment de rol van chetnotherapie is bij patienten met niet-operabele vormen van dikke darm kanker. ongetwijfeld is meer reden dan enkele jaren cleden on chemotherapte te overwegen. Verkleining van tumor en verlichting van klachten gijn realistische resultaten, aij het nog steeds bif een minderheid van de patientem. Dartegenover staan relatief weing bijwerkingem, vooropgesteld dat de behandeling wordt ingesteld en begeleid door terzake kundigen. Patienten met uitgeraaide stadia van kanker van de dikke darm dlenen anno 1990 voor overleg in inultdisciplinalre oncologiebesprekingen en, ma targwuldige afveging van voor en tegem, voor palliatieve chewothe raple in anmerking te komen.

\section{Hoofds tuk III. Motieven.}

Wike misdaad heeft een motlet. Bij het oplossen van een misdaad Hs het zoeken naar het notlef een belangrjjk onderdeel om inzicht te kriJgen in karakter en werkwjze van de dader en potentiele nieuwe slachtoffers tijdig te kumen Warschuren. Zocken naar het motief wordt door fransen wel aangeduld als: "chercher la teme" " mara in geval wan kanker van de dikke darm zullen we de

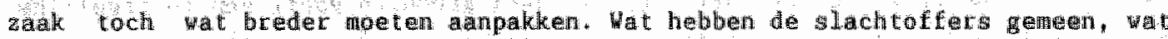
zijn kenterken wan de indulduen, die kanker van de dikke darm ontwlkkelen.

op epidentologische gronden wordt reds lang veritow, dat bepaalde aspecten van de woeding samenhangen met de kane op thet ontwkkelen wan kanker wan de dlkke darin. Deze vertoedens komen onder andere voort uit observaties dat deze 


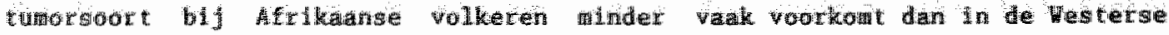

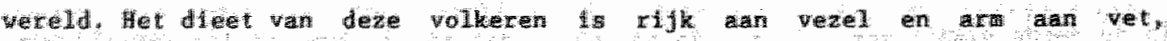

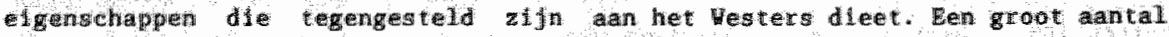

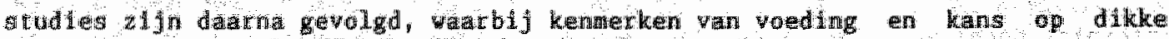
dart kanker 21 fh bestudeerd door vergelljking tussen landen russen 2 streken of 2 bevolkdngsgroepen in én land of tugsen patienten me en controles zonder kanker van de dlkke datm. Dit allm moellllke studlies. Van grote aantallen Wengm moet zo exact mollok finformatie over zo lets complex als onze vording

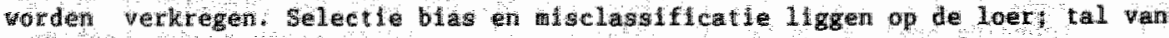

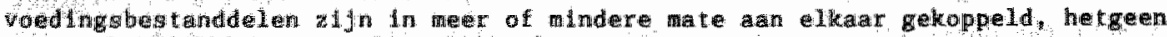
do Interpretatle var gevonden verbanden benoellljkt. Wan alle speurders, die wh thet het Gehel wan de ontarde crypt bezighouden, is de epldenioloog. well het silust the bend jon.

Kanker van de Dikke Dam : Voeding

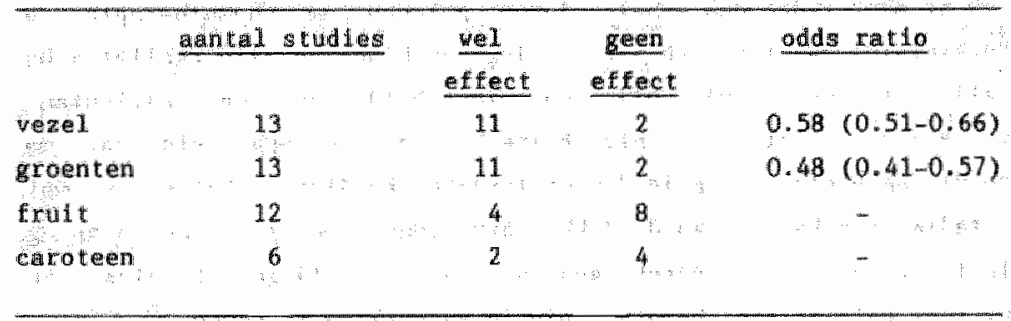

Bron: Trock et I, JNCI 1990; 82: 650-661.

Een van de meest gangbare hypothesen op het gebied van de relatle tussen vaeding en kanker van de dikke darm betreft de inname van vezels. Recent 1 s een overzicht verschenen van alle studies, warin de inname van vezel. is bestuderd In relatie tot kanker van het colon. De resultaten laten ziem, dat een royale Innare van vezels een beschermend effect heet het rislco op coloneareinom

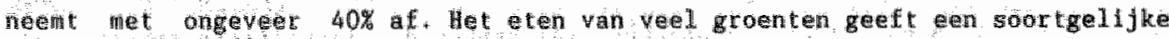
bescherming. Onduldelijk is, of dir effect alleen van de vezels in groenten

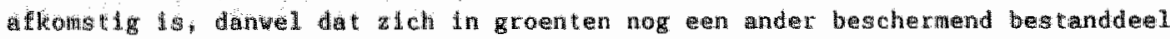
bevindt. Van fruit, cen bron van vitamine $C$ er caroteen, een voorstadium wan witame $A$, $1 j n$. Mn deze neta-analyse geen beshermende eftecten gevonden. 
Hoe kumen wif ans he verbend tussen de consumptie van vezels en het ontstan wan dikke darn kanker het beste voorstellen? vetels aljn slech wht teerbant en konen grotendeels on weranderd in de duke dam terecht. $\mathrm{zj} j$ wergroten dab het wolumen van de darnhmoud en rersnellen de passage. Een van de hypothesen kan wus $2 i j n$ dat zich in de datminhoud kankerverwekkende stoffen bevinden, die door het eten van vezels worter verdund en snelier uitgescheiden. Uit experimenten met proefdieren is bekend, dat een antal stoffen, die zlch nornall in onze dikke darm bevinden, het ontstan van kanker kunnen bevorderen. Daar toe behoren vetzuren, die eventueel va de ga ult de woeding afkonstus zign, secundalre galzuren, die uht de gal ontstax en fecapentaenen, dia dook de bacterien wan de darm worden geproduceerd. De eventule bijdrage yan enk wan deze stoffen aan het ontstan van dikke darm kankez bij de nens is onbekend.

Het vezelverhal leidt tot 2 conclustes. De eerste 19 , dat het slijmulas wan de dikke darm kennelljk van binnenult blootgesteld is aan kankerverweklende

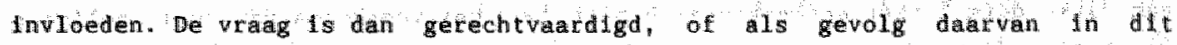

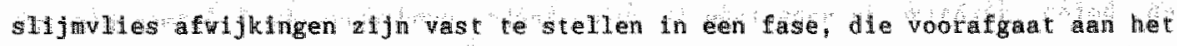

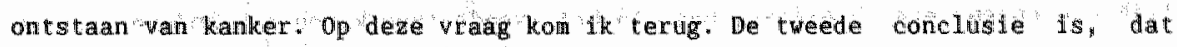
cen vertoogde consumpte van vezels of vezelrjjke voeding een beschermend effect heeft op het ontstaan van dikke darm kanker en de kans hierop met biyna de helft kan verminderen. Deze bevinding zou, veel meer dan nu het geval 1 s, kunnen leiden tot preventleve actle. It plelt er niet voor, dat wa verbodmaatregelen de mens ontdaan wordt van de mogellykheld tisico's to lopen. Leven is ristconemen, wrijheid is de elgen wistco"s te mogen kiezen. Maar kiezen betekent kennts en daaraan ontbreekt het vaak. Ik zou er en lans voor willen breken, dat op verpakte voeding als brood, andere graanproducten, blikgroenten djeprriesmaltijden etc. thet gehalte aan vezels wordt aangegeven en wel als percentage van de dagelijkse hoeveelheid die op epideiniologische grond als beschermend wordt beschourd. Ik kan daar vandaag nog an toevoegen; dat de kederlandse Kankerbestrijding een grote woorlichtingscainame in woorberelding heft, warbij wa de bakkerswinkels kenmis over gezonde voeding, in het blizonder over vezels, wordt verspreid.

Moofdstuk IV. Nog Heer Mot Ieven.

Voor het ontstam van dikke darm kanker zijn nitel alleen omgevingstactoren, In het bizonder voeding, wan belang. Recent onderzoek heeft duidelijk geriatikt, dak 


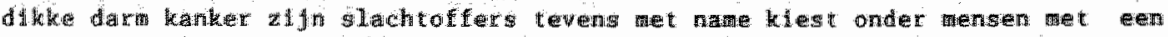

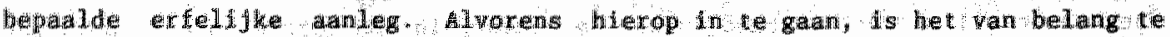

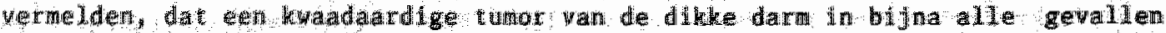

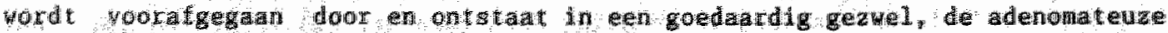

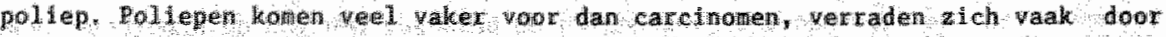
werl les wan bloed we de ontlasting en kunnen nees tal envoud $\mathrm{g}$ met behulp wan endoscople torten werhjderd.

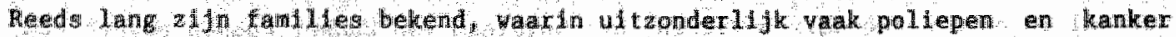

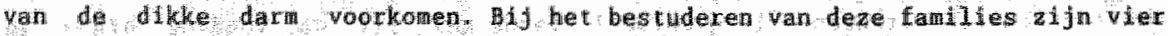
zohtebeldem gevonder In wee darvan de famillaire polyposis coll en het syndroon, an Gardmer, ontwkelen de patienten duzenden pollepen, warvan altijd enkele zul len ontarden tot cen kwadaandig gezwel. Bij het symdroon van Gardner komen bovendien ook budten de dikke datm erfelijke afwijkingen voor. De

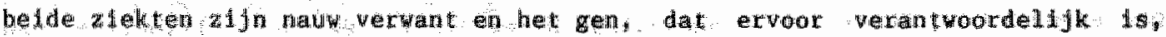
bey Ind tlch op de lange arm van chromosom 5 , be twe andere famllalre vormen yan dikke darn kanker kennetken zich niet door het voorkomen van vee pollepen en heten dorhalve de nonpolypasis colon kanker syndromen. De 2 vormen hiervan $11 \mathrm{ken}$ eveneng erg op elkar, max in het weede type komen ook andere vormen yan kanker vaker dan notmal woor. Het gen voor deze ertelijke vormen van kanket is nog nilet gevonden.

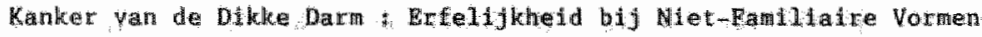

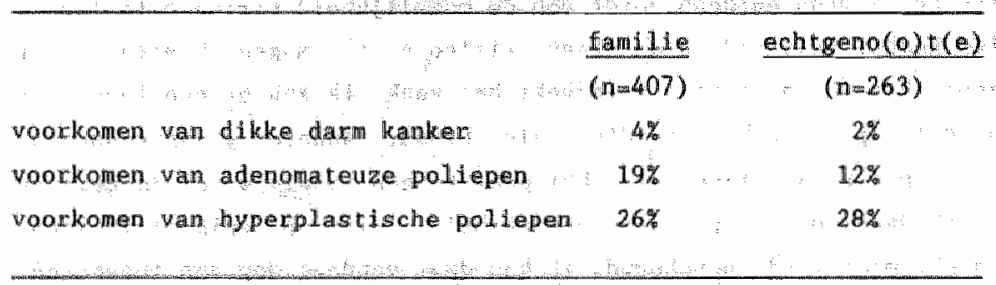

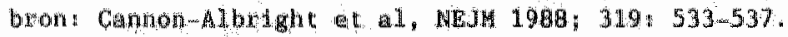

Deqe thelljke vormen van dikke dara kankex, hoewel bjologisch interessant,

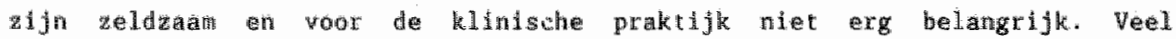
belangrifker 18 , dat et nu anwijzingen zijn voor een enfelifke factor bul het

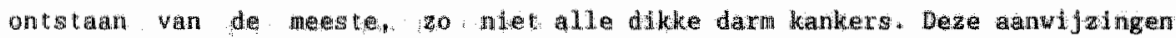


komen onder andere van groep creatieve ondercokers ult de Anerlikanse

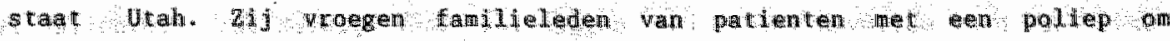
endoscopisch te worden onderzocht op de amwez gherd wan poltepen lin het

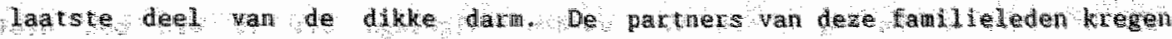
hetzelfde verzoek en dienden as controles met een althans in belangrijke mate overeenkomstige levensstijl en voeding. Negentig procont van de mogelijke kandidaten dat is 670 personen ut 34 tamllies, refigerde positul. Adenomateuze poliepen werden bj $19 \%$ van de familieledem bij 12 van de angetroude fallie angetroffer. Hyperplastische politep, de niet als

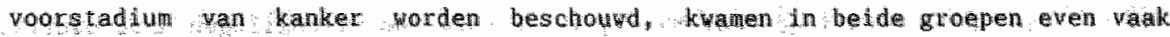
woor. Op basisuan de Fandiegegevens kon varschindigk worden gemalkt; da poliepen bijna altid ontstan in pessonen metreen erfelijk bepalite

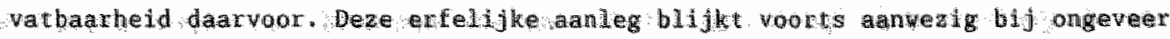

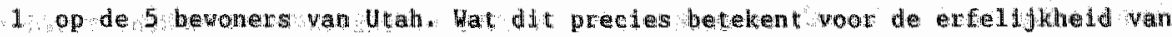
dike darm kanker moev warder woten ondergocht:

Deze bewinding heeft belangrijke gevolgen. Er kan gezocht worden nater het watbarheidsgen yoor dikke darti poltepen, watar de efecten datran op het slijmviles en naar de wijze, warop dt gen met omgevingstactoren samenterk bij het ui teindelijk ontstan van katker. onderzoek heeft inmiddels uitgewezen. dat het op het oog nomale dikke darm slijmvlies tan mensen met poliepen een verhoogde delingsactivitelt vertoont. Deze toestand kan bug proefdieren aok worden berelkt door ze te voederen met een zogenaamd Westers di $t$, dat thlils aan vet en arm aan kalk. Brfelijke aanleg en omgevingsfactoren lifken dus in dezelfde richting te verker, namelijk nar esi toestand van hoge celdelingsactivitelt. Hoe dit in verband stat met de vorming van polieper en carcinomen is nog onbekend en onderwerp wan onderzoek.

Intusser heeft thet erfelijkheidsonderzoek wel praktische consequenties. Pollepen wan de dikk darn komen kennelljk bij aen groot deed wan do bevoling

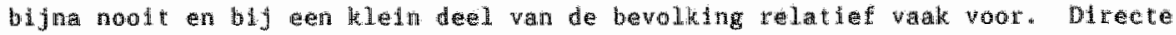
tamilieleder van pacieaten met een pollep of een cardinoom hebben wen

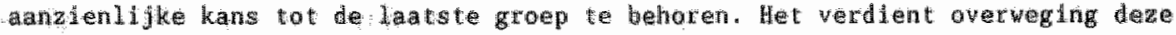
personem ata te bieden in een sereeningsprogramat te worden opgenomen. 


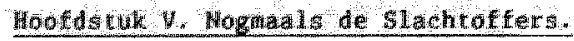

onderzoek nat wotheven leld tot suggestes voo preventue. Preventie is theter lange weg en het hinlsch speurwerk naat betere hulp aan de blachtoffers van nu mag er nlet wom worden stlgelegd. Dit $1 \mathrm{~s}$ dan ook nlet gebeurd en het heeft zelfe tot een opzienbarend succes geleld.

Pat detten, de woor colloncarcinoon zin geopereerd en bij whe tumorcellen lin de Hymfllieren van de dike darm zijn gevonden, hebben een kans wan $40 \%$ a $50 \%$

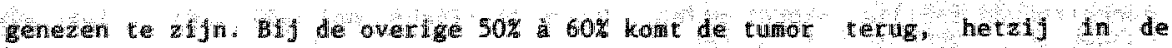
butrt van het operatlegebled, hetzif in de vorm van ultzadingen nar elders. net mame de lever. Op goede gronden wordt mangenomen, dat deze ultzalingen in microscoplsche vorn lanvezig $21 \mathrm{fn}$ op het moment van de operatie Dit leldt tot de gedachte deze patienten direct na de operatie met cytostatcal te behandelen tet de bedoeling deze wicroscopische witualingen te doden, woordat ze tot grotere uitzatisngen zifn utgegroeld. Hervan veten ve inmers, dat ze ntet meer the genezen zijn.

Kanker wan de Dikke Darm: Aduvante Theraple met PU-Levanisol

\begin{tabular}{|c|c|c|c|c|}
\hline$\cdots$ & & controle & nabehandel ing & $!$ \\
\hline antal patdenten & & 315 & 304 & $\cdots$ \\
\hline antal recidleven & & 155 & 103 & \\
\hline barekende recldlefk & & $\because$ & & \\
\hline na $3 y_{2}$ jaar & & $53 \%$ & $37 \%$ & \\
\hline antal overledenen & & 114 & 78 & \\
\hline berekende sterfkans & & $\cdots: \quad: \quad$ & $\because \quad: \quad$ & \\
\hline na 34 Jar & & $45 \%$ & $29 \%$ & . \\
\hline
\end{tabular}

Dukes" C patsenten met coloncarcinoom.

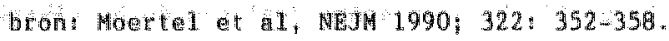

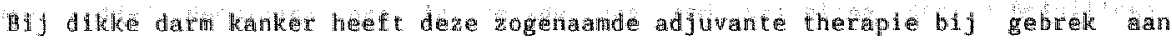

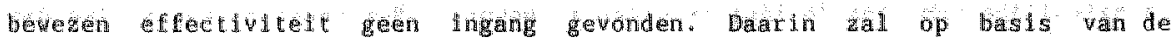
resulkaten vin een Anerlkanse stude vetandering noeten kowen. In dexe studie werd de helfe van de patienten met tumormbettende lymfklteren na de operathe 
gedurende 1 jar behandeld get een combinatle van 5 Fu en levathsol: de andere

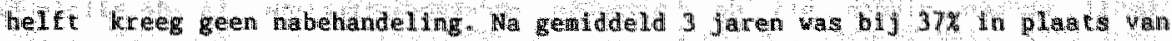
537. van de patienten de 2 tekte teruggekeerd. Op bas $1 \mathrm{~s}$ van deze getallet $11 \mathrm{Hht}$ het genezungpercentage van dit stadw vam coloncarclnoon thet ongever eenderde te kunnen vorden vergroot.

vat betekent di $t$ woor de Nedle landse sltutiel per jaar $21 \mathrm{gn}$ ongeveer 6000 patlenten met coloncarcinoon te verwachten. Hervan heeft ongeveet $30 \mathrm{~g}$ bI operatie tumor-bevattende lymfkI lieren. $\mathrm{Br} \mathrm{zIn}$ dus per jaat ongeveer 2000 patlenten net dit stadum van le zonder nabehandeling met 5 vo ben levamisol. ongeveer $40 \%$ (dat is 800) en met deze nabehandeling ongeveer $55 \%$ (dat is 1100) genezen zouden worden. Wet andere woorden, ongeveer 2000 pathenten noeten behandeld worden on 300 patienten extra te genezen. De overige 1700 patienten krijgen deze nabehandeling zonder er baat bly te hebben het 1 j ondat ze toch al genezen zijn (800), hetzij ondat ze ondanks de nabehandeling nlet genezen worden (900): Wet deze getallen z1jn de Ingredienten wan het wedisch dllemm aangegeven: 300 mensenlevens gered en 1700 minloze behandelingen; die vel met bijwerkingen als misselifkheld, braken, ontstoken slijawlezen en harul tval geparard kunnen gaan.

Er is ook een finaricleel dilemma. Ex zijn flinke kosten verbonden aan 50 pollklinische infusies van 5Fu, tabletten levamisol, pollklinische controle valn bijwerkingen en behandeling van complicaties. Een voorzlchtlige schatting leert, dat dit voor 2000 patienten met de huidige tarieven best eens op 30 m11joen gulden per jaar kan uitkomen. Dit betekent dan, dat elke extra geneing wordt berelkt woor een bedrag wan 100.000 gulden.

Ik heb we worgaande berekeningen met opzet in detall witgevoerd, ondat do resultaten ervan een goede Indruk geven wam de problemen, waarmee woorultgang In medische kennis en techniek gepard gat. Duidelifh is, dat datablj tegenower iedere uinst kosten stam, zovel medisch als tinaricled. Hetere

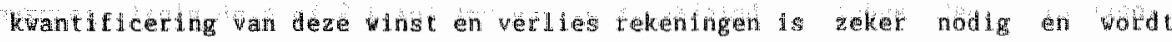
onder andere nagesteefd door investeringen, wan de afde wan de overheld en

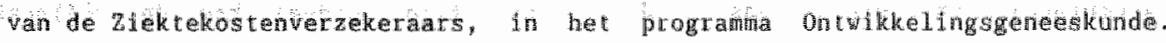
Darbil passen vel enkele opmerkinger. 


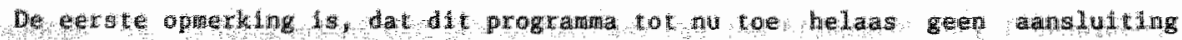

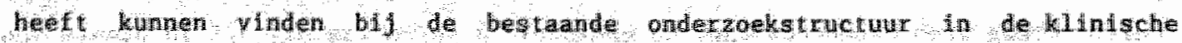
oncologle Wergel Jkend onderzock van geneesmiddelen. giat ook yan andere vormen wa bethandeling als chirurge en tadotheraple wordt al jaren in Buropecs of natlonal verband verticht onder auspletem van de EORTC en de

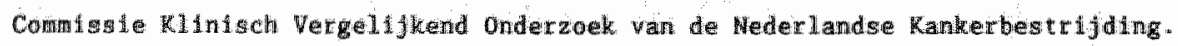

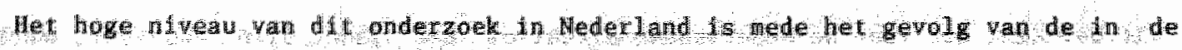

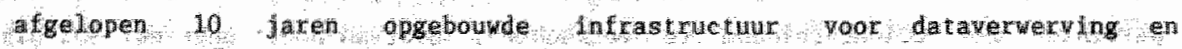

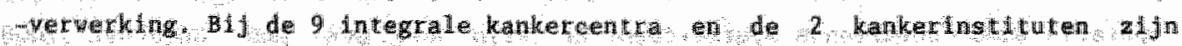
dartoe datanasers angested, die de trait dualon vormen tussen de behandelend arta en $1 \mathrm{j}$ dossler enerzljus, de cobrdinator wan de sudie anderzijds Deze infrastructuur vord op dit moment geheel geflnancierd door de

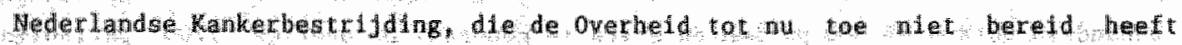

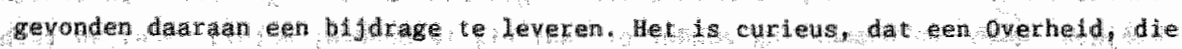
ons del Hl opzadelen met een tamellj bizar yoorstel om de pris van geneesmadelen te reduceren zo velnig geinteresserd is in de zinen on in van het yoorschrljven darvan. dar voor dit unleke systeen van oncologisch data

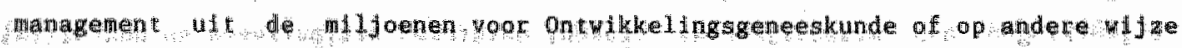
gen geld kan worden gereserweerd. Samenwerking tussen de comisgie ontwikelingsgeneskunde de comisste kilinisch vergelijkend onderzon van de Nederlandse KankerbestriJding kan deze Impasse wellicht doarbreken

Een wede opmerking is, dat exacte berekentngen van wht en verlies, medisch en fuancigel, ons nooft gullen ontslaan yan de verplichting ulteindelijk ethische of politieke oordelen ta vellen. Hoever is emensendeven waard, in

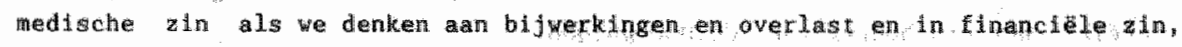
als we denken an de kosten per genezen pattent in relatie tot andere behoeften wan de matschapplj. He moet bij deze belangrijke dilemmás het oordeel vellen?

Wat betrefe het medsch dulerma gat het on kansen van individuen In ons voorbedid: nabehandeing beteknt voor cen patient $15 \%$ kans op winst fenezen

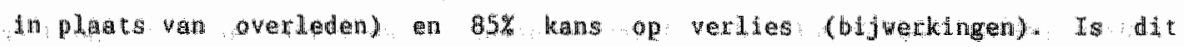
acceptabel wie bepalt dat? Nar mijn oordiel kan de medische acceptabiliteit in latste instantle allew door arts ren patient gevanenlijk vorden wastgesteld. Hoe zij dit doen, hoevel en welke woorden zij daarbij 
gebruken, delke overneglingen darbil de doorslag geven deze zaken behoren tot het domein van de arts-patuent nelatie. overleg lussen en met destundigent consensus-afsprakem protocollering in het keder wan bijwanbeld de

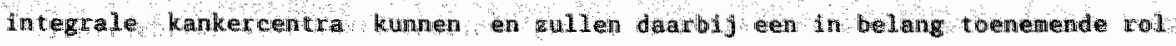
spelen zonder echter de subjectivitelt wan de individuele beslissing gehed te kurnen vervangen.

Het inanclele dilema gaat on afwegingen van kosten tegen andere kosten in de getandheidszorg en daarbulten. In ons voombeld is hiler de vraag, ot 100.000 gulden per patientacceptabel is en le dat bepalt, Dewe taag ls heden ten

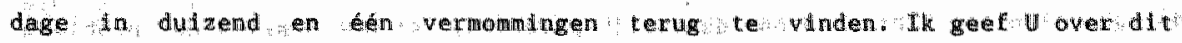
complexe probleem enkele persoonlijke gedachten. Mensen hechten meer dan ari endg ander aspect van het leven aan de gezondheid van glehzelf on hui nadsen, zo is wit onderzoek gebleken. De flnanelering wan de getondhetdsong ds dan ook wia de afdracht van premles in belangrijke mate gertcht op individuele inwestering in eigen welzijn. Volgens het Centrabl Bureau voor de statistek wordt $90 \%$ uan de 2500 gulden, die per jaar per hoofd van de bewolking aan gezondheldszorg wordt utgegeven, op deze vijze opgebracht Dantegenover stat, dat afweglngen over de kosten wan inde gewondheldsworg tn tomenende mate bij de overheld lijken te belanden. Deze blljkt vaak mex geinteressevd In de hoogte van bedragen dan in de inhoudel ijke kant, een punt financiale: benadering dis door Hoody Alten aot ts samengevat in de zin "Dyng is an exceldent way to cut down on expenses. "Tlustratlef hiervoor is de discusste rond de onamyaardbare wexkdruk van verpleegkundigen. Dit is cen zorginhoudel jik probleen dat door de overheid lange tijd pooral finaricieel is: benaderd. Net de vraag: "Hoe lossen we dit op en wat is de ral van de premiebetaler darin" stond central, maat het probleem: "Meer premle is meer loon en dus via de koppeling druk op uitketingen". Het ziektekostenvaagstuk

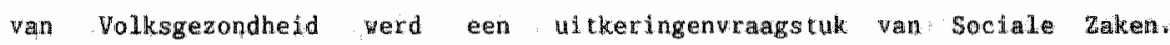

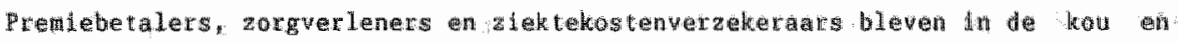
met de actues aiturer.

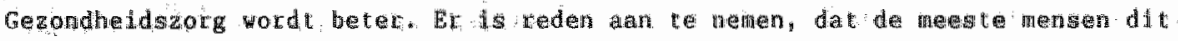

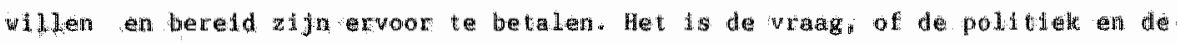

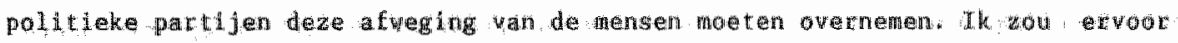
wllen pletten, dat de financlele dilema's in de gezondheldszorg worden gellegd 


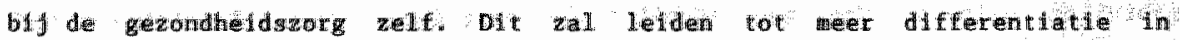

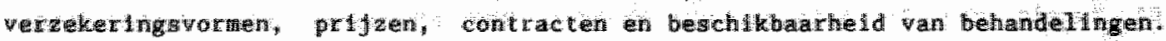

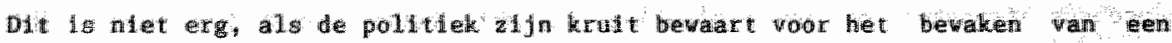

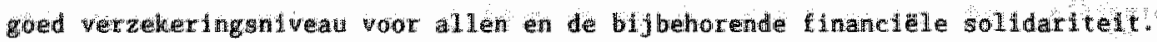

In de huldige gezondheidszorg lidt ook en wooral succes tot problemen en Ik Gis ex enkele genoem. Als de nabehandelling met 5 pu en levamisol ook van nut bllkt bly minder ver woortgeschreden stada van coloncarcinoon en bill rectucarcinoomi en daar $11 \mathrm{kt}$ het op, word het succes nog groter en zullen Jaar11Jks wellicht 1000 merigen met deze zlekte extra genezen kunnen worden. wit de getulien t echter tevens duldelijk geworden; dat ook daarmee het probleem wan dikke datu kanker verte wan opgelost is. Het word dus tlyd on de zak meer fundamenteel te benaderen, ons te wenden tot het onderzoek naar de toedracht vart de hisdafind dartoe echit in de crypt af te dalen.

Hoofostuk WI De Toedracht.

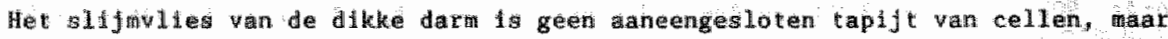

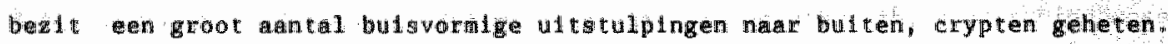
War het 11 jowlies mede doör de passerende darmunhoud voortdurend aan slijtage onderhevig is, mith of meer zoals biy een tapijt warover gelopen wordt vindt in de crypten productie van eellen plats. die de kale plekken van een nteuve bedekhing voorzien. Celaandakk is dus én van de belangrijkste functies van de crypten. Onder nomalle ontstandigheden worden per dag in de crypiten net zowed nlevwe cellen angemakt als er door sllytage aan het oppervlak verloren gaan. op wonderbarlijke wjoe blifte op deze manier het systeem precles in eventeht.

In eval van tumorgroel gat dit ewentcht verloren. Er worden meer cellen genalatet dan nodig zifn. Deze cellen hopen zich op en for ontstat een adenomatetu pollep. Herbij zal het valk niet bligven. In de poliep kunnen wich kwadardige cellen ontwkkelef. In dat geval gaat het niet meer alleen on een tevel atu celler, mar ook on cellen met een abnornal gedrag. Zij blijken in satat de ongeveride weefsels birnen te dringen, cen proces dat bekend stat

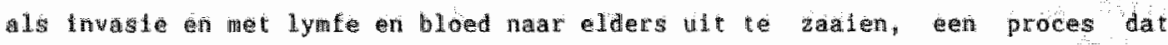
metastasering heet. Tijdens deze processen treedt wisselwetking op net andere 


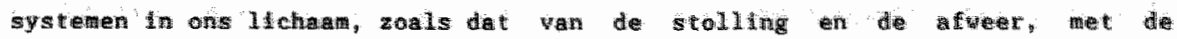

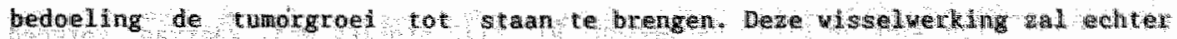

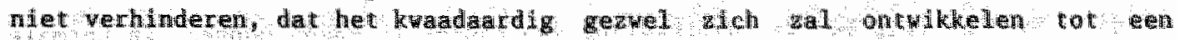

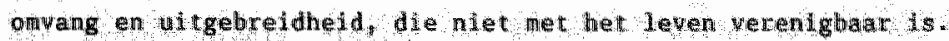

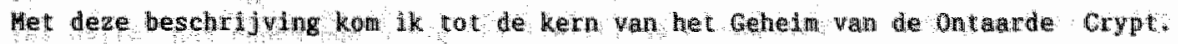

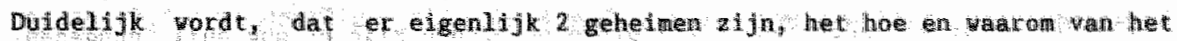

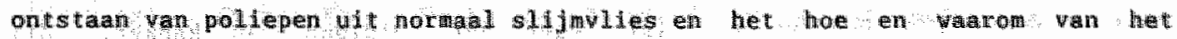

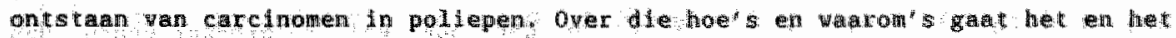

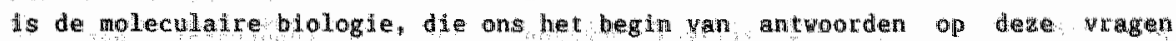
heet verschaft:

In een misdaadroman komen spewders voor, die gich in het bizonder bezighouden met het afriemen en bestuderen van vingerafdrukken. In het biochem sch speurverk wordt de rol yan dactyloscoptaten lagemonen door de noleculair blologen. Hun vingerafdrukken bevinden $z$ Ich in het felijk material, dat In de vorm van on In we celkern aanvezig is. Met verbazingwekkende prectsie zien wil kang afwljkingen: in dit DNA In kaart te brengen en de beteken ls dararan woor het gedrag van cellen te ontrafelen.

Kanker wan de Dikke Darm : Genetische Veranderingen

\begin{tabular}{|c|c|c|c|}
\hline mormale cellen & functie: & $\therefore$ & kanken edler \\
\hline & ब & s? & $\therefore$ \\
\hline proto-oncogenen & groe beworderend: & $\therefore$ & activitie \\
\hline \multirow[t]{4}{*}{ (RAS, mye, ele, } & groteifactoren & $\therefore \quad:$ & nutatie: \\
\hline & receptoren & & translocatle \\
\hline & signat transduet & ies . & ampliticatie \\
\hline & lemeine it ten & $\therefore \quad$ & $\therefore \quad \therefore$ \\
\hline & & $\therefore$ & : \\
\hline ant 1 -ancogen & foredremend: & & Magt 1 wal 10 \\
\hline (suppressor genen) & kerriel to ten & $\cdots$ & mititid the \\
\hline$\left(\mathrm{Bb}_{4}, \mathrm{~F}\right.$ & ant 1 -anfiogemse & & delet \\
\hline
\end{tabular}




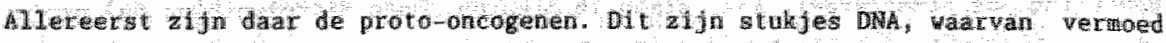

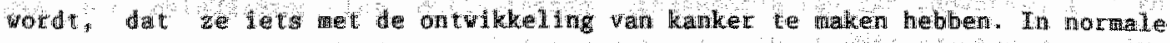
staat an deze genen onder andete van belamg wor morwale oroelprocesser van de cel, zoals het opvangen, doorgeven w veruerken van groelstimlerende

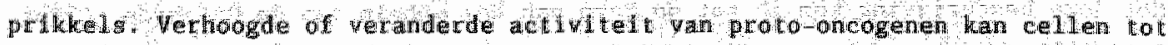

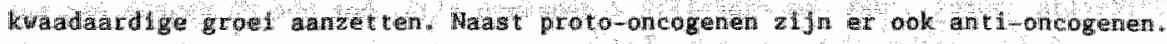
Weze 3 tukfes DNA begchermen Julst tegen het ontstan van kanker. Zij onderdrumket abnomale grael en theten dan ook vel suppressor genen. hun precleze functe to nog valgwel bnbelkend; wan én supptessor gen is gebuggerwerd, dat: her de voor kwataardige groel go kentherkende

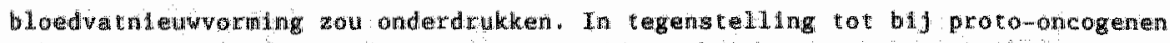
wa fulst verlaagde activited of verlies wan and-oncogenen tot watadardige groel humen blfdragen. Oncegenen en antl-oncogenen aljn belangrifhe determanter In de dellcate balans, de ons llcharm in steat stelt tot nawgeget a der behoef te angepaste groel processen.

Wanker van de Ddke Darm a Genetische Veranderingen

\begin{tabular}{|c|c|c|c|}
\hline 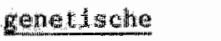 & adenona & euze: & carcinotaen \\
\hline \multirow[t]{2}{*}{ afulikingen } & polde & en & $a r$ \\
\hline & klasse I & Kasse II & \\
\hline mutatie RAS & $13442 \%$ & $57 \%$ & $47 \%$ \\
\hline delet le chr.s & $29 \%$ & $29 \%$ & $36 \%$ \\
\hline delet le ch. 17 & $6 \%$ & $24 \%$ & $75 \%$ \\
\hline deletie chr. 18 & $11 \%$ & $47 \%$ & $93 \%$ \\
\hline
\end{tabular}

klasse I : geen tekenen van kraadatadigheld, meestal klein $(66 \%<2 \mathrm{~cm})$

Llasse II: met tekenen van kgatdardigheld, metsis gitot $(95 \%>2 \mathrm{~cm})$

brons Wogelstefn et al, NGM 1988; $319: 525-532$.

Gevend met dege noodwakelijkerwijs zer oppervlakkige beschrijving van de granetische basis van kanker, kijken we nu naw poliepen en carcinomen van de duke darm en stellen de vraag, of we lets wan deze mogelijke DNA afwjkingen kunnen terugvinden en of de goedaardige gezwellen daarim ran de kwadaardige 
verschll lem, Het anwoord is voorloph Ja en nee on dit te llustreren mak $1 \mathrm{k}$ gebruit van gegewers wan onder woekers ut de verenigde staten de in samenverking net de Universiteit wan Letden genetlsche treranderingen bestudeerden bij poltepen en bij carchomen van de dikte dam be poutepen

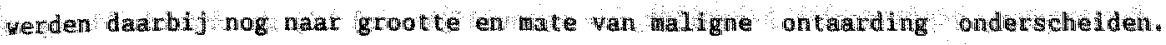
Van de proto-oncogenen blljkt het RAS-oncogen van betekenls w $\mathrm{f}$ ongeveer $30 \%$ van zowel de goedaardlge als de kwaadaardig tumoten werd een abnorman

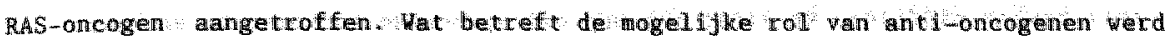
gekeken war verlies van delen van de chromosonen 5,17 en 18 . Verlles wan delen wan chromosoon 5 werd bij ongeveer bénderde van de goedaardigo en kwaadaardige gezvellen getien. Dit werlies trad op in het gebied wan chromosoom 5 , waar al ch ook het gen vior de erder besproken exfellike vormen wan polyposis coll bevind verlies var delen van chromosoon 7 en 18 was frequent bif carcinomen en alinder frequent blj pollepen met name do kleinere prormen .

Deze en soortgelijhe gegevens zijn zo interessant; ondat ons woor het eerst een bllk gunnen in het bimenste wan de ontaarde crypt. Dite blik laat ons kennelijk niet de hele wimte pvertien en geft ons mog nat alle antwoordien.

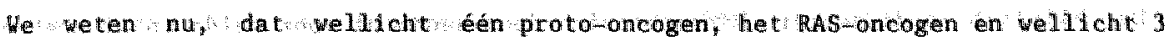
suppressor gemen, gelokaliseerd op de chromosomen 5,17 en 18 en rol spelen bij het ontstan van godardige en kwadaardige gezwellen van de dikke darm. Het gehele Geheim wordt Gons echter: nitet onthuld, Geen van de gevonden fuljkingen js kenmerkend wor carctnomen in vergeltjking met pollepen of voor poliepen in vergelijhing met northal silJmviles. Veertg procent van de heel kleine poliepen vertoont gén enkele afwljking h het RAS-oncogen of op de 3

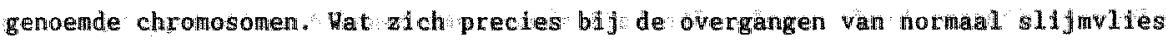
naar premallgne slijmwlies natr goedaardige poliepen naar kwadaardige careinomen woltrekt, blijft dus toch mog voor een belangrijk deel aan ons grezichtsweld ont rokken

Moleculatr biologisch onderzoek is niet slechts spielerei voor anbltieuze onderzekers; Inzicht in de betrokkenheid varn genen en genproducten bul het ontstaan tan abnormale groel kan leiden tot geheel nieuwe votmeri van diagnostiek en theraple. Woor de diagnostiek kan men denken aan het maken van indiwduele risicoproflelen woor dikke dartin kanker op bastis van thet al of nlet 


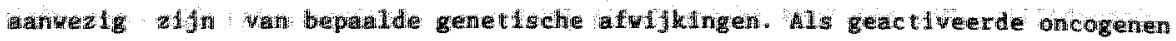

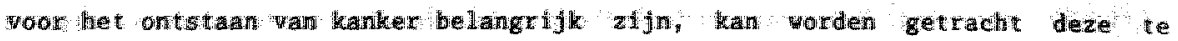

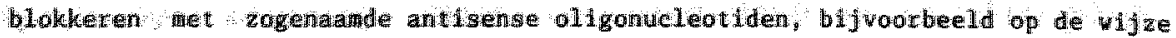

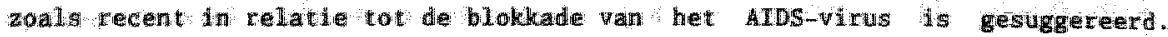

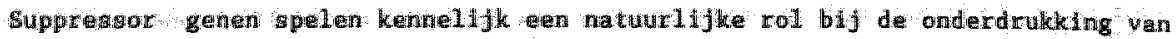

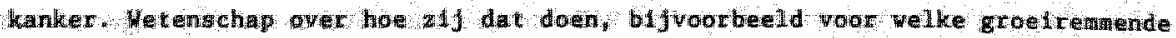

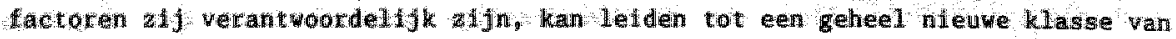
ant 1 ikanker mddelen. Br staal ons nog een spanneride toekonist te wachten.

Hootdstou WIIT. De Speurder:

Aan dequger van cen snelstromende rivler ergens in trika stain 2 dealisten,

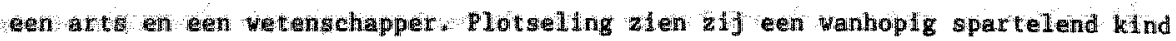
voorbly dif 1 ven. $21 \mathrm{f}$ stimgen in het water, het kind wordi gered. Kort dagrme, alwer wand in het water. Met vereende krachten worden a diverse kinderen aan land en tot leven getracht. De arts zegt: "Ik denk, dat het nut tig is hiter een eerste hulp post in te richten." Vaarop de wetenschapper antwoord: "Ik ta boven aam de waterval maar ens klyen we die kinderen in het water goot $k$.

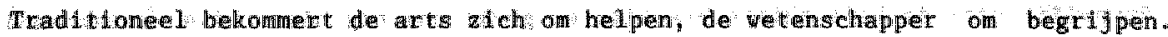

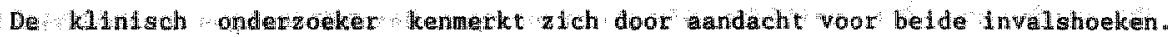

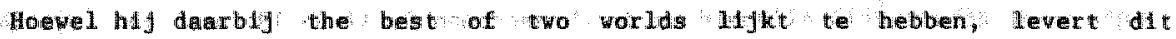
tegelifkerthd het probleen op, dat hlj op belde fronten wet voor wol wordt angezten. Voor de collegamarts is hit tevel de onderzoker, die met studies,

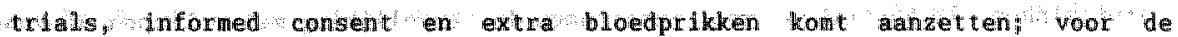
preklinische wetenschapper is wij de goedwillende wateur, die alls het moethly wordt toch een blomedicus inschalkelt omet onderzoek lin goede banen te lellen. Deze kartkaturir heeft, zoals elke karikatuur, een bepald warheldsgehalte De academisch medisch speclalist beheerst niet de dactyloscopie noich is hij de polithe-psycholoog voon s lachtof ferhulp wat hem kenmerkt is het vermogen

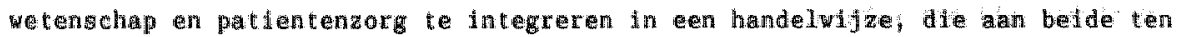
goede kont: De karkatuw heft ateh tan op in en nieuw portret, dat wan de

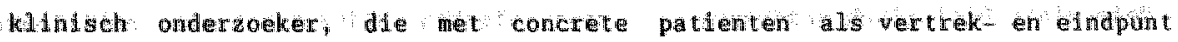

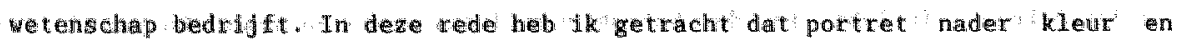
glans. tevers. 


\section{Havorord}

Uiteraard is het portret wan een klinisch onderzaeker een groepsportret. velen

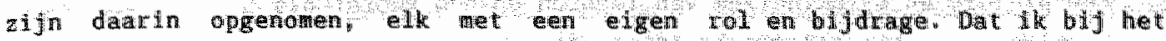
sabenstelien wan dit portret wat vereerwoudighing heb moeten aanbrengen, spreakt

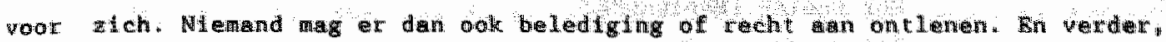
een goed portret spreelk voor zldhzelf en $\mathrm{k}$ zal er dus geen woorden meer an ringen.

Ben groepsportret is een weergave van het hle en nu verleden en achtergrond komen niet goed ut de verf. De verlefding is groot dit goed te maken door nog eren groot wantal anderen in woord en beeld te laten passeren. Ih zal dit niet doen. Ik 2 al er slechts 3 noemen, die th in het blander als foljn leermeesters beschouw en die bovendien de drie landstreken vertegenwoordigen, dte voor mijn loopbaan van betekenis zifn gewest.

Frits Keuning, indertlyd hooglerar Histologle en Mcroscoplsche Anatomie ir Groningen, leerde nij experimenteel onderzoek te zlen als onderdeet wan en dienstbaar an de exploratie van fundamentele biologische concepten en hypothesen. Hif zocht inzicht, geen kunstjes en dat is nuet zo wanzelisprekend als het $11 \mathrm{jkt}$.

Emil J. Fredrelch indertijd hoofd wan het Department of Developmental Therapeutlos van het M.D. Anderson Cancer Center in Houston, Texas, leerde m dat elke patient een potentieel woorwerp en onderwerp van onderack its. $213 \mathrm{n}$ optimisme, dat alleen op deze wijze kanker owerwonnen kan forden, was niet hol mat gevuld met creativitelt dat is niet zo vanzelfsprekend als het lijkt.

Van Guns Flendrig, tenslotte, heb it al doende kunner leren, hoe in de complexe vereld van de acadenle een visle op een afdellng Interne Geneeskunde tot

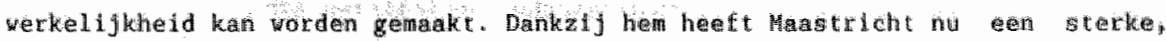
niet uteengevalien acadenische Interne Genesklunde en dat Is wilet zo vantelfsprekend als het $11 j k t$.

In deze 3 leerneesters ill ik allen danken, die it het verleden of op de achtergtond an mign ontwkkeling en die van de Haematologie en oncologle in Mastricht heben bifgedragen.

Bn de famille dan? Wel, van je famille moet je "t hebben en ald weten wat $1 \mathrm{k}$ datrinee bedoel. 


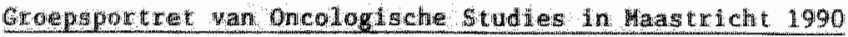

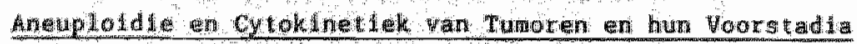

- colon Leorold Rngels (strand)

cotauter (Hed Lunde)

Eno Bosman (Patiologie)

gurath

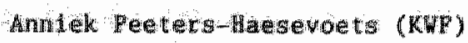

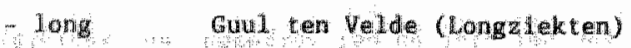

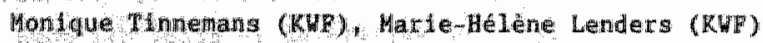

- Hodghtr. Har 1 sehouton

Hank Erdkamp (Endhoven

Nin) Dred (E Indhowen)

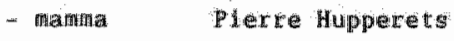

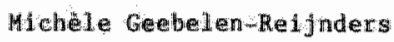

- oweral bretschutte (Celbiologle)

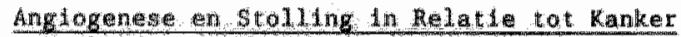

Hat L L L chenbeld

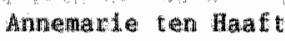

Karly Hamulyak

R.i.je Yan ban (biochemie)

Puct Mulder (Blochemle)

\section{Kindsche studies}

beenumerams tantate

- Dick wan thenen, haremalogen/oncologeru Verplegktundigen 3 , Sazanne Joogken

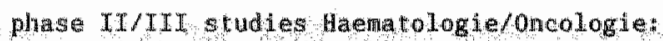

Arno Smals, haenatologen/oncologen

oncologische specialisten AZM

Jecques HLs (Roeronon), TKL college en medewerkers

Sylvia Gort, NLcole Bakder, Anny Peeters

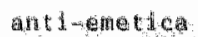

- Max 1 jke van Dongenomotis

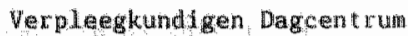

Whitelit wan leven

: Jean simons

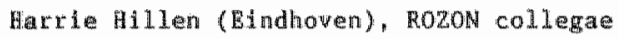

atode enougal

- Heke Haemercis 
Tenslotte nog dit: Wie van $\mathrm{U}$ wat eerder deze aula binnenkwa kon Iwsteren naar muzlek. Bruno Walter, 76 jaren oud en leerling van Gustaw Mhack. begeleidde de Britse alt qathleen Ferrier in het laatste lied van Das Lled voll der Erde. Dit is én van de laatste opnamen van perrier, korte tije daarma

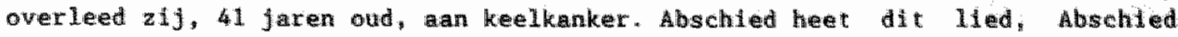
was het wor de jonge Kathien Ferrler, afschedd nemen hoort biy mijn soort patienten en bij mijn vak. Met dit lled en deze uitvorring heb lk deze diffveer willen aangeven.

\section{Veruldzingen}

1. Vademecum Gezondheldsstatistlek Mederland 1989. Uitgever CaC en Minsterie WC. 1989.

2. Eimhorn l.F. Improwements in fluorouracil chenotherapy. J Cin oncol 1989: 7 : $1377-1379$.

3. ErnstofE $4 S$. Fluorouracil, interferon-alpha and colon cancer: rational pursuit of symergism between antimetabolites and biologicals. J clin oncol 1989; 7 : $1764-1765$.

4. Ardalan $B$ et al. A randomized phase I and II study of short-term infusion of high-dose Eluorouracil with or Whout PALA in patients wth advanced pancreatic and colorectal cancer. J clin oncol 1988; 6: 1053-1058.

5. Trock B et all. Whetary fiber, wegetables and colon cancer: critical review and meta-analysis: of the epidemiologic evidence. J Natl Cancer Inst $1990 \% 62$ : $650-661$.

6. Camnon-Albright LA et al. Common inheritance of susceptibility to colondic andenomatous polyps and assoclated colorectal cancers. N Engl I Med 1988; 319 : $533-536$.

7. Hoertel $C G$ et al. Levamisole and fluorouracil for adjuvant therapy of resected colon carcinoma. N Engl I Med 1990; 322: 352-358.

B. Buyse Met al. Adjurant therapy of colorectal cancer. Why we stll dons know. JAMA $1908 ; 259: 3571-3578$.

9. Nemark HL al. Colonje hyperplasia and hyperprollferation induced by a nutritional stress diet with four components of Vestern-syle det. jNat Cancer Inst 1990; $02: 491 \% 496$.

10. Weinberg RA. Oncogenes, anti-oneogenes and the molecular bases of multstep carcinogenesis. Cancer Res $1999 ; 49: 3713-3721$.

11. Vogelstein B et a1. Genetic alterations during colorectal tumor development. W Engl J Ked 1988; 319: 525-532.

12. Nowe11 PC. Mollecular events in tumor dewelopment. N Engl 3 Med 1988; 319 : $575-577$ 